\title{
S24. New antipsychotics: present and future (supported by an educational grant from Sandoz $\mathrm{CH}$ )
}

\begin{abstract}
D1, D2, D3 AND D4 DOPAMTNE RECEPTORS: STRUCTURE AND POTENTIAI, RELATION TO ANTIPSYCHOTIC EFFECT. Peter H. Andersen.

Department of Molecular Pharmacology, Bioscience. Novo Nordisk a/s. Novo allé, Blgn 1C.23, DK-2880 Bagsvaerd, Denmark.
\end{abstract}

Dopamine receptors have classical been divided into D1 and D2 receptor subtypes. However, a number of data indicated that this two subtype scheme was too simple (see Andersen et al., TiPS, 11. 1990). The greater diversity was confirmed by molecular biology in 1990 and 1991. So far, five different genes encoding functional dopamine receptors have been identified. These receptors belong to the $G$ protein coupled receptor superfamily and have been termed D1a, D1b (or D5), D2, D3 and D4. Pharmacologically, these five receptors can still be classified as a D1 and D2 family, consisting of D1 a and D1b and D2-D4, respectively.

The $\mathrm{D} 1 \mathrm{a}$ and $\mathrm{D} 1 \mathrm{~b}$ receptors have al the classical D1pharmacological features - high affinity for NNC 687, $\mathrm{SCH} 23390$ and clozapine, low/no affinity for spiperone and sulpiride and is coupled in a stimulatory fashion to adenylyl cyclase. The D2, D3 and D4 receptors is classical D2-like showing high affinity for spiperone and low affinity for NNC 687 and SCH 23390 and is coupled in am inhibitory fashion to adenylyl cyclase.

The D1a and D2 receptors have a widespread localization in all major dopaminergic areas. The D1b, D3 and D4 receptors, on the other hand, seem to have a very restricted localization primary in limbic areas.

No antagonists with substantial selectivity within these receptor families is available at present. Consequently, a detailed analysis of the importance of each receptor subtype in mediating antipsychotic activity is troublesome.

\author{
A POTENTIAL NEW ANTIPSYCHOTIC DRUG WHICH \\ INTERACTS WITH D-1 RECEPTORS \\ R.Markstein,R.Amstutz,A.Jaton, "St.Urwyler, ${ }^{\text {C. }}$. Ruedeberg, ${ }^{\text {A A.Imperato. }}$ \\ Preclinical Research Sandoz CH-4002 Basle,'Sandoz Research Institute \\ CH-3033 Berne,"University of Cagliary, Italy
}

The unique therapeutic properties of clozapine have been attributed to combined blockade of $5-\mathrm{HT}_{2}$ and $\mathrm{D}-2$ receptors or preferential blockade of D-4 receptors. However, clozapine also differs from conventional neuroleptics by occupying both D-1 and D-2 receptors at therapeutic doses. Thus, D-1 receptors might be a target for atypical neuroleptics. SDZ DOD-647 is a novel drug suitable to test this hypothesis. Ligand binding studies reveal a high affinity to D-1 receptors sites which is 8 times higher than to D-2 sites. The affinity to D-4, 5-HT 2 and muscarinic receptors is low. SDZ DOD-647 inhibits apomorphine-induced rearing in mice and D-1 agonist-stimulated motility in rats, but fails to block apomorphine-induced stereotypies and to induce catalepsy in rats. In awake rats, SDZ DOD-647, like to clozapine, produces a long lasting increase of extracellular dopamine content in the striatum, nucleus accumbens and prefrontal cortex. This effect is prevented by pretreatment with a selective D-1 agonist indicating that it is mediated by $\mathrm{D}-1$ blockade. After repeated administration extracellular dopamine concentration in the nucleus accumbens and prefrontal cortex is elevated. Repeated administration of SDZ DOD-647 does not alter the density of striatal D-2 receptor sites in the rat. Thus, SDZ DOZ-647, like clozapine appears to produce a partial but balanced blockade of D-1 and D-2 receptors and to indirectly enhance dopaminergic tone in the prefrontal cortex. These actions might provide efficacy against positive and negative symptoms of schizophrenia in the absence of extrapyramidal side effects. Since SDZ DOD-647 is a mixed D-1/D-2 antagonists but exhibits low affinity to $5-\mathrm{HT}_{2}$ and $\mathrm{D}-4$ receptors it is also a suitable candidate to test the hypothesis that mixed D-1/D-2 blockade but not a high $5-H_{2} / D-2$ selectivity or a high affinity to D-4 receptors is responsible for atypical neuroleptic properties. 
PET-STUDIES ON D1- AND D2-OCCUPANCY IN CLOZAPINE TREATED PATIENTS Lars Farde. Anna-Lena Nordström. Svante Nyberg. Göran Sedvall. Christer Halldin

Dept of Clinical Neuroscience, Karolinska Hospital, S-171 76 Stockholm, Sweden.

The hypothesis that the antipsychotic effect of classical antipsychotic drugs is mediated by blockade of D2-dopamine receptors has been supported by studies with Positron Emission Tomography (PET). A high degree of central D2-dopamine receptor occupancy $(70-89 \%)$ has been demonstrated in patients treated with conventional clinical doses of such drugs. We have reported a significantly lower D2-occupancy of 38 $-63 \%$ in an initial series of five patients treated with clozapine, the prototype atypical antipsychotic drug. During treatment with clozapine there is a low frequency of EPS which accordingly may reflect the comparatively low D2-occupancy.

We have now examined D1- and D2-occupancy in an extended series of 11 clozapine treated patients. The selective D1-dopamine antagonist $\left.{ }^{11} \mathrm{C}\right] \mathrm{SCH} 23390$ and the selective D2-dopamine antagonist

$\left.{ }^{[11} \mathrm{C}\right] \mathrm{raclopride}$ were used as radioligands to determine receptor occupancy in vivo. The daily doses of clozapine were between 300 and $600 \mathrm{mg}(\mathrm{n}=11)$.

The D1-occupancy was 33-59\% (mean 45, SD=8\%) and the D2occupancy was 38-66\% (mean 52, SD=10\%). These results indicate further that clozapine induces a low central D2-dopamine receptor occupancy as compared to classical neuroleptics.

The combination of a comparatively low D2-and high D1-occupancy is a unique property of clozapine. In the present study the combined D1and D2-occupancy was $78-125 \%$ (mean $97 \%, \mathrm{SD}=16$ ). This observation supports the view that a combined D1-and D2-occupancy may be related to the atypicality of clozapine.

DOES 5-HT, BLOCKADE CONTRIBUTE TO THE EFFECT OF ANTIPSYCHOTIC DRUGS? FOCUS ON RISPERIDONE AND SEROOUEL

O Benkert, $\mathrm{H}$ Wetzel. A Hillert

Department of Psychiatry, University of Mainz, Untere Zahlbacher Str. 8, D-55131 Mainz, Germany

It has been suggested that a balanced $5-\mathrm{HT}_{2} / \mathrm{D}_{2}$-like antagonism might contribute to an "atypical" antipsychotic response pattern.

Risperidone is a potent antagonist at cloned human $5-\mathrm{HT}_{2}, \mathrm{D}_{2}$ and $D_{4}$ receptors. Moreover, $\alpha_{1}$ and histamine $H_{1}$ receptors are blocked to a substantial extent. In an 8 wecks' double-blind study of 388 schizophrenic patients, risperidone $(2,6,10$, or $16 \mathrm{mg} /$ day $)$ was examined against haloperidol $(20 \mathrm{mg} /$ day) or placebo. Analysis of CGI severity, PANSS total score and PANSS positive subscale demonstrated superior efficacy of 6,10 , and $16 \mathrm{mg}$ risperidone and $20 \mathrm{mg}$ haloperidol to placebo. Moreover, 6 and $16 \mathrm{mg}$ risperidone were significantly better than haloperidol in PANSS total score. Compared to placebo, risperidone $(6$ and $16 \mathrm{mg}$ ) resulted in a significant reduction of the PANSS negative subscore. Incidence of extrapyramidal side effects was higher under $16 \mathrm{mg}$ risperidone or $20 \mathrm{mg}$ haloperidol while $6 \mathrm{mg}$ risperidone did not differ from placebo in this respect. In an own open clinical trial in major depression with mood-congnient or moodincongruent psychotic features, risperidone improved both psychotic and depressive symptoms.

Seroquel induces a moderate blockade of $5-\mathrm{HT}_{2}$ receptors and a relatively weak antagonism of $D_{2}$-like dopamine receptors. Its antiadrenergic properties are less pronounced, and antagonism of muscarinic acetylcholine receptors is virtually lacking. In a small placebocontrolled study in schizophrenic patients, seroquel in doses up to 250 molday resulted in a psychopathological improvement in all 8 verum patients. In contrast to these results, an overall clinical response rate of about $33 \%$ was observed in an own open clinical trial in 12 schizophrenic patients with predominantly positive symptomatology under seroquel in doses up to $750 \mathrm{mg} /$ day. Seroquel did not induce extrapypramidal side effects in either study. Data of double-blind studies vs. placebo and chlorpromazine are currently being evaluated.
CLASSIFICATION OF ANTIPSYCHOTIC DRUGS. FOCUS ON D1 ANTAGONISTS, CLOZAPINE, OLANZEPINE AND SERTINDOLE Jes Gerlach

St. Hans Hospital, Dept. P, DK-4000 Roskilde, Denmark

The division of antipsychotics into atypical and typical (classical/traditional) neuroleptics is an untruitful simplification which may lead to misunderstandings in both human clinic and biochemical science (for example, when two "atypical" drugs with very different pharmacological features are presumed to cause similar effects). A classification based on pharmacological characteristics is more constructive, e.g. a classification into (1) selective dopamine receptor antagonists (such as D1 and D2 antagonists); (2) multiple receptor antagonists (such as clozapine and risperidone); and (3) non-dopamine drugs. Each of these classes can then be easily subdivided into relevant subgroups.

D1 antagonists are interesting because they in primate models exert a stronger anti-amphetamine effect and milder EPS profile (less dystonia and dyskinesia) than D2 antagonists. A D1 antagonist, NNC 01-0687 is under clinical evaluation. Maybe a combined blockade of D1, D2, D3 and D4 dopamine receptors represents the strongest potential (cf. clozapine)

Clozapine causes a relatively mild blockade of $\mathrm{D} 1$ and $\mathrm{D} 2$ receptors (including D3 and D4) as well as a relatively strong blockade of $5 \mathrm{HT} 2 / 3$, $\alpha 1, \mathrm{H} 1$ and $\mathrm{M} 1$ receptors. Clozapine is still the most potent antipsychotic drugs improving more than a third of otherwise poor responding schizophrenic patients. Due to its various side effects, however, it is important to search for alternatives.

Olanzepine has a receptor binding profile resembling that of clozapine, with a relatively mild $\mathrm{D} 2$ receptor blockade, but in addition, as clozapine, with blockade of $\mathrm{D} 4,5 \mathrm{HT} 2 / 3, \alpha 1, \mathrm{H} 1$ and $\mathrm{M} 1$ receptors. Open studies suggest that this drug has a strong antipsychotic effect and few side effects.

Sertindole is unique by producing its main effect via a selective depolarization block of limbic dopamine neurons. It binds to 5HT2 and $\alpha 1$ receptors, but only very mild to D2 receptors. Clinical studies indicate that sertindole has antipsychotic effect with few and atypical side effects. 